\title{
Environmental Education: A Correlational Study among Environmental Literacy, Disaster Knowledge, Environmental Sensitivity, and Clean-Living Behavior of Post Tsunami Disaster in Aceh Communities, Indonesia
}

\author{
Rusli Yusuf $^{1 *}$, Muhammad Yunus ${ }^{1}$, Maimun Maimun${ }^{1}$, Iwan Fajri ${ }^{2,3}$ \\ ${ }^{1}$ Department of Civic Education, Universitas Syiah Kuala, Kopelma, Darussalam, Banda Aceh, Aceh 23111, Indonesia \\ ${ }^{2}$ Department of Civic Education, Universitas Pendidikan Indonesia, Bandung, Jawa Barat 40154, Indonesia \\ ${ }^{3}$ Center of Disaster Studies, Universitas Islam Negeri Ar-Raniry Banda Aceh, Aceh, 23111, Indonesia
}

Received: 8 May 2021

Accepted: 24 June 2021

\begin{abstract}
This research aims to determine the correlation between literacy, disaster knowledge, and environmental sensitivity towards clean living behavior of communities in disaster-prone areas. The data was collected through questionnaires and analyzed by statistical software. 385 respondents from three different regions, coastal, urban, and inland took part as respondents. The results indicated that more than half of the people have a very high attitude towards cleanliness (\%) 63.10, environmental literacy 61, and environmental sensitivity 52.70. but less than half respondents $45.50 \%$ had good knowledge about disaster. Environmental education variables have marginal homogeneity between environmental literacy and disaster knowledge (49\%), disaster knowledge with environmental sensitivity (28\%), and environmental sensitivity with clean living behavior (23\%). There are no significant differences in coastal, urban, and inland communities' attitudes towards environmental literacy, environmental sensitivity, and disaster knowledge. However, the perspective of clean-living behavior was significantly different between the three areas. The people aged 46-65 years have a better clean-living behavior and disaster knowledge. Based on gender, the male group had a better knowledge of clean-living behavior, environmental literacy, and disaster knowledge, while the female group had a better environmental sensitivity. The research revealed that there is a common understanding of environmental literacy, environmental sensitivity, and disaster knowledge in coastal, urban, and inland communities. The
\end{abstract}

*e-mail: rusliyusuf@fkip.unsyiah.ac.id 
results also indicated that people in cities have a better understanding of clean living compared to rural and coastal communities.

Keywords: environmental literacy, disaster knowledge, environmental sensitivity, clean living behavior

\section{Introduction}

The tsunami in Aceh, Indonesia that occurred on 26 December 2004 has provided valuable lessons for the people of Aceh in particular and Indonesia in general. International assistance to accelerate the recovery of Aceh development in various development sectors has provided community independence to manage postrecovery Aceh development. The development of the environmental sector is one of the important points to foster a public attitude in maintaining environmental cleanliness and safety. Previous research has not been carried out to evaluate public awareness in maintaining the safety of the post tsunami disaster environment. This research is a topic of environmental education related to environmental literacy, disaster knowledge, environmental sensitivity, and clean-living behavior. The four components of environmental education are problems often complained by the local government, but the fundamental problems have not yet been really answered.

Moreover, community members need to be responsible for creating awareness, appreciating, and understanding the importance of a healthy natural environment, manifested through environmental literacy [1]. Therefore, it is necessary to improve environmental cleanliness behavior following stipulated expectations [2]. The disaster knowledge and its relationship with environmental behavior is another important aspect. By understanding disasters and their mitigation, the community would prepare earlier when the disaster happened. Considering Indonesia as a disaster-prone area, it is essential to improve every individual's knowledge through environmental education [3].

Furthermore, environmental knowledge is a vital variable mediated by various emotions that promote its behavior [4]. It is possible for any community that lacks environmental knowledge to be destructive and cause disasters. However, human nature's positive aspect improves policies used in overcoming environmental problems. Religious leaders and scholars also need to embrace environmental knowledge and a proenvironmental attitude [5-6].

Pro-environmental is affected by environmental knowledge obtained from formal educations [7]. Therefore, creating a positive community behavior requires adequate efforts to build environmental concern. Because it is determined by environmental knowledge and sensitivity as expressed in the action to manage the environment [8]. Besides, a positive environmental attitude realized through environmental knowledge is mainly felt when there are materialistic values and high self-awareness [9]. Therefore, the ability of the community to understand and overcome these problems involves the possession of positive knowledge and attitudes towards the environment pursued through related literacy [10].

Consequently, appropriate environmental behavior is observed in its proper management, supported by environmental literacy skills [11]. It is also correlated with environmental knowledge and attitudes towards the environment [12]. Increasing knowledge, developing habits, skills, and attitudes, and forming values related to the environment need to be pursued through environmental education [13]. Some countries integrated environmental education in the subjects such as science, biology, geography, ecology, and social sciences [14]. In comparison, other countries designed it as a separate education [15]. In Indonesia, the K.13 curriculum was developed to design an integrated learning process and create a well-behaved community, including a positive behavior and attitude towards the environment.

Studies and policies regarding environmental issues such as disaster education and school safety management [16], sustainable school disaster preparedness [17], as well as evaluation of building performance for post-disaster reconstruction [18], have been carried out. People in Indonesia, particularly Aceh, did not fully understand the concept of disaster knowledge, environmental literacy, sensitivity, and cleanliness behavior. Mostly carried out after the tsunami attacked Aceh in 2004. Furthermore, the research on public and Islamic school students' environmental literacy following programs from the central government has also been carried out [19]. After over 17 years of the disaster, the pro-environmental awareness among young generations seems to fade away and decline gradually. Because a natural disaster can repeat itself, the knowledge about it must be sustained in the school curriculum. The young generations should be aware of the repeating catastrophe in the future.

Maintaining pro-environmental awareness in the future required the proper knowledge associated with environmental behavior and attitudes. Therefore, this research is crucial because it aims to identify how the Acehnese community's environmental literacy and disaster knowledge correlated with environmental sensitiveness and pro-environmental attitudes.

Environmental literacy is an individual's knowledge of environmental concepts, problems, attitudes, cognitive abilities, beliefs, skills, and behaviors related to this context [20]. It is also defined as the ability to understand, interpret environmental systems, and take appropriate steps to maintain, restore, or improve these conditions [21]. Scholz and Binder [22] defined it from two perspectives. Firstly, the knowledge of 
environmental work methods is the central pillar of science. Secondly, science also contributes to explaining how humans interact with the environmental systems to create environmental literacy. Environmental literacy tends to carry out research, investigations, and analytical skills to learn about the environment and ways of dealing with its problems (NAAEE, 2000). Adequate knowledge about the environment is essential because humans are making a significant contribution to the environmental issues through industrial waste, domestic waste, and vehicles. Therefore, raising awareness among the community is in great need and crucial [23].

Several studies imply that environmental literacy is carried out to prepare individuals or communities to understand better and overcome environmental problems [24]. The community's poor environmental literacy is associated with several factors, such as lack of environmental content of curriculum at all education levels, uninformed community with proper knowledge of environment and disaster, and inadequate environmental-related information published through mass media [25]. According to Simmons [26], The attributes of environmental literacy include 1) Attitudes towards the environment, 2) Ecological Knowledge, 3) Socio-political knowledge, 4) Environmental knowledge, 5) Cognitive skills, 6) Responsibility towards environmental behavior, and 7) Additional determinants of behavioral responsibility. Therefore, this research explores environmental literacy's effect on disaster knowledge and sensitivity towards environmental cleanliness behavior in the community.

DL is described as knowledge or experience related to events that are harmful to human life, thereby leading to casualties and other losses caused by natural and non-natural factors [24]. Disasters due to biological factors are often caused by earthquakes and floods, and climate changes [27]. It is also caused by improper behavior in protecting the environment and lack of disaster knowledge, which causes damages [28]. Therefore, there is a need to prevent, reduce or avoid potential losses due to disasters, which is realized by ensuring rapid and appropriate assistance for victims and obtaining quick and effective recovery procedures [29]. In a more superficial dimension, disaster is also interpreted as an event that causes environmental damages, misery, or human discomfort.

Furthermore, people often encounter disasters due to their poor environmental cleanliness behavior. In order to overcome this problem requires disaster knowledge based on individual experiences in the form of evaluation, attitudes, points of view, commitment, and motivation. It has been realized that knowledge development is one of the solutions in reducing disaster risk. Therefore, knowledge management plays an essential role in ensuring the availability and accessibility of accurate disaster risk information through effective learning [30]. However, this research focuses on finding the relationship between community behavior regarding environmental cleanliness and disasters knowledge

Geographical literacy tends to instill disaster knowledge in students. While nurses and other health personnel need to embrace disaster education and training methods. Moreover, other studies stated that the use of all phases of knowledge management ensures its benefits in reducing the disaster's impact and increasing resilience [31]. Based on the literature, no research has been carried out on the relationship between disaster knowledge and environmental cleanliness behavior and attitudes. Therefore, this study is focused on the aspects previously mentioned.

A person's sensitivity to the environment is often interpreted as an environmental attitude. In addition, environmental attitude or sensitivity is described as the beliefs, responses, effects, and actions of a person related to their environmental activities [32]. These attitudes are shown in the mindset or response to environmental problems [33]. Consequently, an individual is able to address all matters related to the environment, including the natural, political, economic, and cleanliness aspects. Therefore, as earlier reported, this study also tries to find a relationship between environmental attitudes and cleanliness using the Environmental Attitudes Inventory.

The results of this research have also been frequently realized, although they have not been proven to relate to disaster knowledge and community behavior regarding environmental cleanliness. Furthermore, it was concluded that environmental attitudes are related to environmental knowledge. Conversely, knowledge associated with nature promotes each individual's ecological attitudes and behavior [34]. Some other studies have also reported that students actively maintain and preserve the environment due to awareness [35-38]. One of the aspects examined in this research is the effect of environmental sensitivity on community' behavior regarding environmental cleanliness.

Clean living behavior is considered as one of the variables associated with all forms of environmental health care [39]. The community still displays certain behaviors that do not comply with environmental cleanliness standards, such as inadequate ventilation, unhygienic beds, and overcrowding. Some people still do not understand the importance of clean water, sanitation, and environmental cleanliness [40]. However, certain behaviors such as littering, shabby, and inadequate bathing environment, with poor toilet facilities, leads to an unclean community. Therefore, in this research, the concept of environmental cleanliness behavior is defined as the behavior of members of a society in their environment with respect to cleanliness.

Several research results on environmental cleanliness behavior were obtained as a basis. there is a relationship between individuals and their clean behavior in society. Subsequently, there is a metaphorical relationship between environmental cleanliness, morals, and behavior [32]. Pro-environmental behavior relates to 
humans with a compelling sense of empathy towards animals and surroundings. Some other studies reported that the students' environmental behavior needs to be improved by working together in the community [41]. There is a positive correlation between energy-saving behavior and greenhouses, although enormous changes need to be made in human behavioral patterns based on the environment [42]. Based on the literature review, environmental cleanliness behavior, especially in the Indonesian communities, also needs to be determined.

This research focused on investigating whether environmental literacy and disaster knowledge of the Acehnese community impact the Acehnese community's environmental sensitivity and cleanliving behavior in three areas of Aceh province. The purpose of this study was to evaluate the correlation between environmental literacy, disaster knowledge, and environmental sensitivity toward the clean-living behavior of the community at Aceh province.

\section{Material and Methods}

\section{Respondents}

This research was carried out in nine regencies or cities in Aceh province. This province consists of rural areas located north of Sumatra Island in the Indonesian archipelago's westernmost part. The total population was represented by randomly selecting nine regencies from the center (Bener Meriah, Gayo Lues, and Aceh Tengah), the urban (Aceh Besar, Banda Aceh, and Pidie), and coastal areas (Aceh Jaya, Aceh Barat, and Nagan Raya). Following the minimum sample size, 385 participants were selected based on the following assumptions (a) residents of disaster-prone areas, (b) regions with the most waste producers, (c) more than 16 years old, and (d) have lived in the current location for at least three months. The final sample characteristics are shown in Table 1.

\section{Research Instruments}

The instruments were developed based on the work conducted by Tuncer et al. [43], which was intendedly designed to measure the environmental literacy. The knowledge of disasters was evaluated using a survey questionnaire adapted from a disaster preparedness evaluation tool developed. The instrument for assessing environmental sensitivity was developed accordingly. While assessing the community's clean living behavior the respondents were asked to choose alternative answers according to their respective situations and their understanding of environmental issues. The instrument was developed based on certain community conditions and adjusted to each variable's needs with 50 items. All items were developed based on 5 Likert's scales with the following criteria: $5=$ strongly agree; $4=$ Agree; 3 = Neutral; 2 = Disagree; and 1 = Strongly disagree.
The reliability and environmental education variables were analyzed using statistical software (SPSS) version 22. Respondents' attitudes or knowledge data (age, gender, and area) regarding environmental literacy, disaster knowledge, environmental sensitivity, and clean living behavior were analyzed using the Kruskal-Wallis test. Meanwhile, the ranking was analyzed using the Wilcoxon Signed Ranks Test. The correlation between variables was determined using path analysis by software analysis of a Moment Structures (AMOS) 23.0.

\section{Results and Discussion}

\section{Instruments' Validity and Reliability Test}

Descriptive statistical analysis was carried out to obtain an understanding of the overall data. Table 2 showed that clean living behavior had an average value of 3.86, which exceeded the environmental literacy (3.63, SD 0.41), disaster knowledge (3.49 SD 0.55), and environmental Sensitivity (3.66 SD 0.50) variables. The results showed that the community has a high environmental behavior regarding cleanliness in urban, inland, and coastal areas. It is determined and also affected by environmental sensitivity and literacy. The instrument's reliability and validity were assessed, as depicted in Table 2.

After being distributed based on the variables, the data was analyzed to categorize each variable's trend. It is referred to as the calculated average score. Therefore, organizing the tendency of respondents' answers into scales was carried out using the following formulation: minimum score $=1$; maximum score $=5$; and scale width $=\frac{5-1}{5}=0,8$. Trend scale categories with interval $1.00-1.80$ (very poor), 1.81-2.60 (poor), 2.61-3.40

Table 1. Respondent demography.

\begin{tabular}{|c|c|c|}
\hline Demographics of the Research Sample & N & Percentage \\
\hline \multicolumn{3}{|c|}{ Gender } \\
\hline Male & 140 & 36.4 \\
\hline Female Age (years) & 245 & 63.6 \\
\hline \multicolumn{2}{|c|}{} \\
\hline $26-25$ & 110 & 28.6 \\
\hline $46-65$ & 190 & 49.4 \\
\hline $65+$ & 60 & 15.6 \\
\hline Cluster Area & 25 & 6.5 \\
\hline Coastal & 105 & 27.3 \\
\hline Urban & 175 & 45.5 \\
\hline Inland & 90 & 23.4 \\
\hline
\end{tabular}


Table 2. Reliability and validity scores of instruments and descriptive statistics of research variables.

\begin{tabular}{|c|c|c|c|c|c|c|c|c|}
\hline Variable & $\mathrm{N}$ & Mean & St. Dev & Min & Max & Number of items & Cronbach's alpha & Validity \\
\hline Clean Living Behavior (CLB) & 385 & 3.86 & 0.43 & 2.87 & 4.87 & 15 & 0.914 & 0.775 \\
\hline Environmental Sensitivity (ES) & 385 & 3.66 & 0.5 & 2.5 & 4.9 & 10 & 0.912 & 0.754 \\
\hline Environmental Literacy (EL) & 385 & 3.63 & 0.41 & 2.75 & 4.75 & 15 & 0.947 & 0.821 \\
\hline Disaster Knowledge (DK) & 385 & 3.49 & 0.55 & 2.2 & 4.7 & 10 & 0.934 & 0.721 \\
\hline
\end{tabular}

(moderate), 3.41-4.20 (high), 4.21-5.00 (very high). Based on the data analysis, the trend distribution in environmental literacy and sensitivity, disaster knowledge, and community's environmental behavior.

\section{Marginal Homogeneity of Variables}

This research examines the sensitivity of people living in coastal, urban, and inland areas to protect the environment. Environmental education variables assessed include environmental literacy, environmental sensitivity, disaster knowledge, and clean living behavior. People from the three regions have relatively high affinity and activity to protect the environment based on research findings. Specifically, each environmental education variable is considered to have different perspectives from the people who live in these three areas.

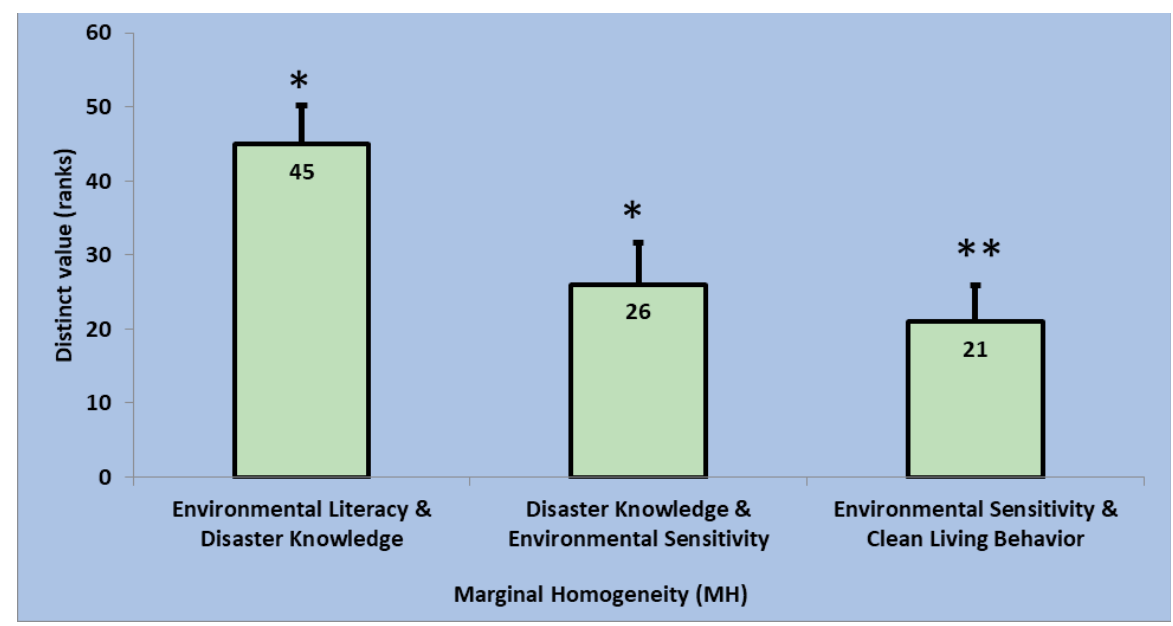

Fig. 1. Marginal homogeneity of environmental education variables. Environmental literacy and disaster knowledge groups have better marginal homogeneity, followed by a disaster knowledge group with environmental sensitivity and environmental sensitivity with clean living behavior. Bar (Distinct value) and bar error (standard deviation).

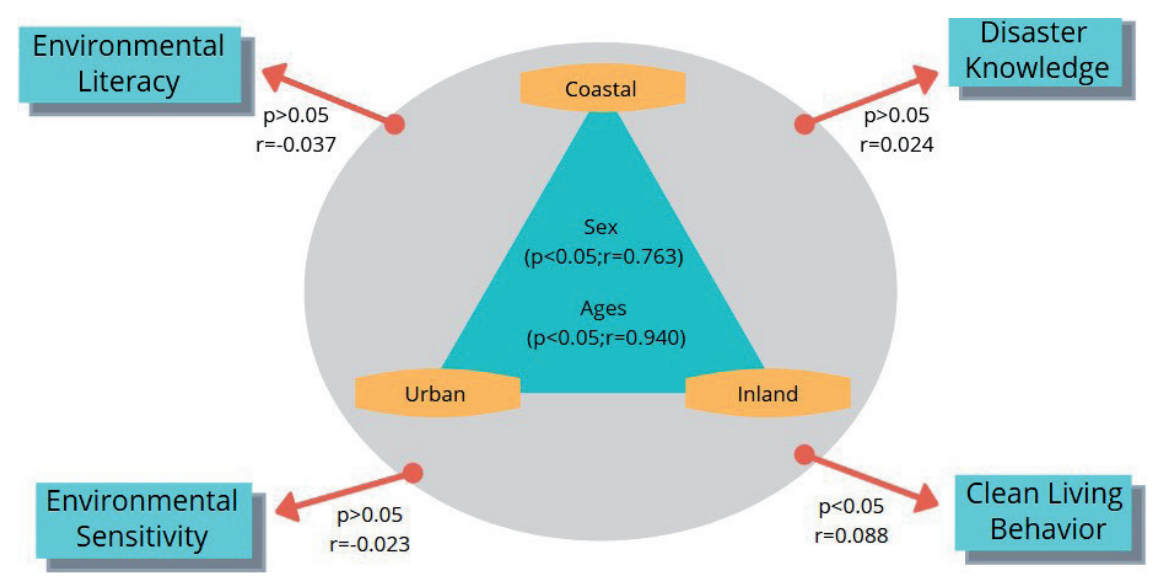

Fig. 2. Environmental education perspective of coastal, urban and inland communities. The three regions have the same environmental education perspective related to environmental literacy, disaster knowledge, and environmental sensitivity. In contrast, clean living behavior has different viewpoints among the three coastal, urban and inland areas. 


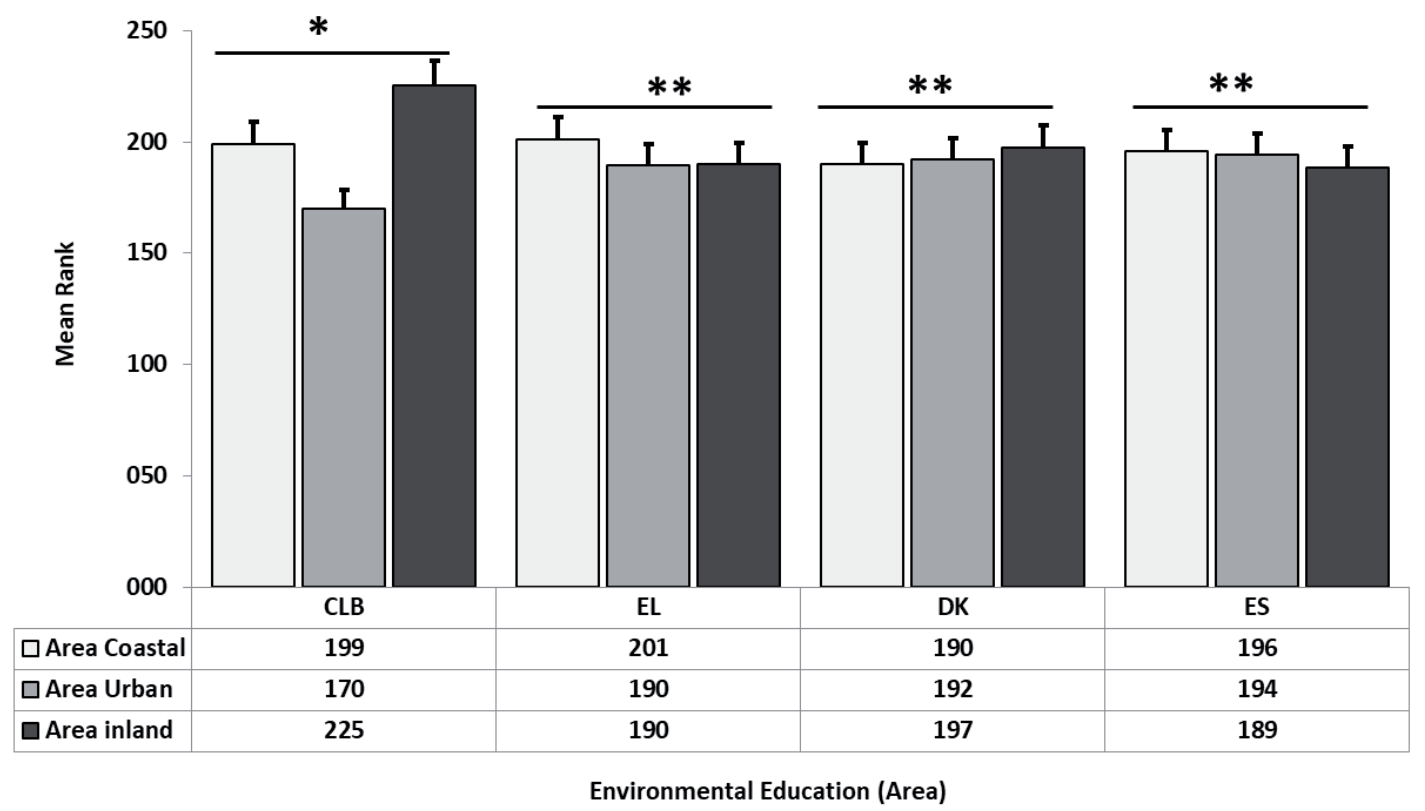

Fig. 3. Environmental education in perspective of coastal, urban and inland areas. Respondents from the inland area have sufficient knowledge of clean-living behavior (CLB), and disaster knowledge (DK) compared to urban and coastal areas. Meanwhile, coastal responder areas better understand environmental literacy (EL) and environmental sensitivity (ES) compared to urban and inland areas. Bar (Mean rank of area), Bar error (Standard error). $(* \mathrm{p}<0.05)$ and $(* * \mathrm{p}>0.05)$.

Generally, Fig. 1 presents the marginal homogeneity between environmental education variables. Environmental literacy with disaster knowledge has excellent marginal homogeneity. Then proceed with disaster knowledge with environmental sensitivity and followed by environmental sensitivity with clean living behavior. In Fig. 2, it is generally illustrated that the attitudes of people who live in coastal, urban and inland areas. These three regions tend to have the same philosophy regarding environmental education (environmental literacy, environmental sensitivity, and disaster knowledge). Meanwhile, the perspective of clean-living behavior shows that there are differences between the three areas.

Based on the evaluation of the homogeneity variable, it shows that environmental literacy with

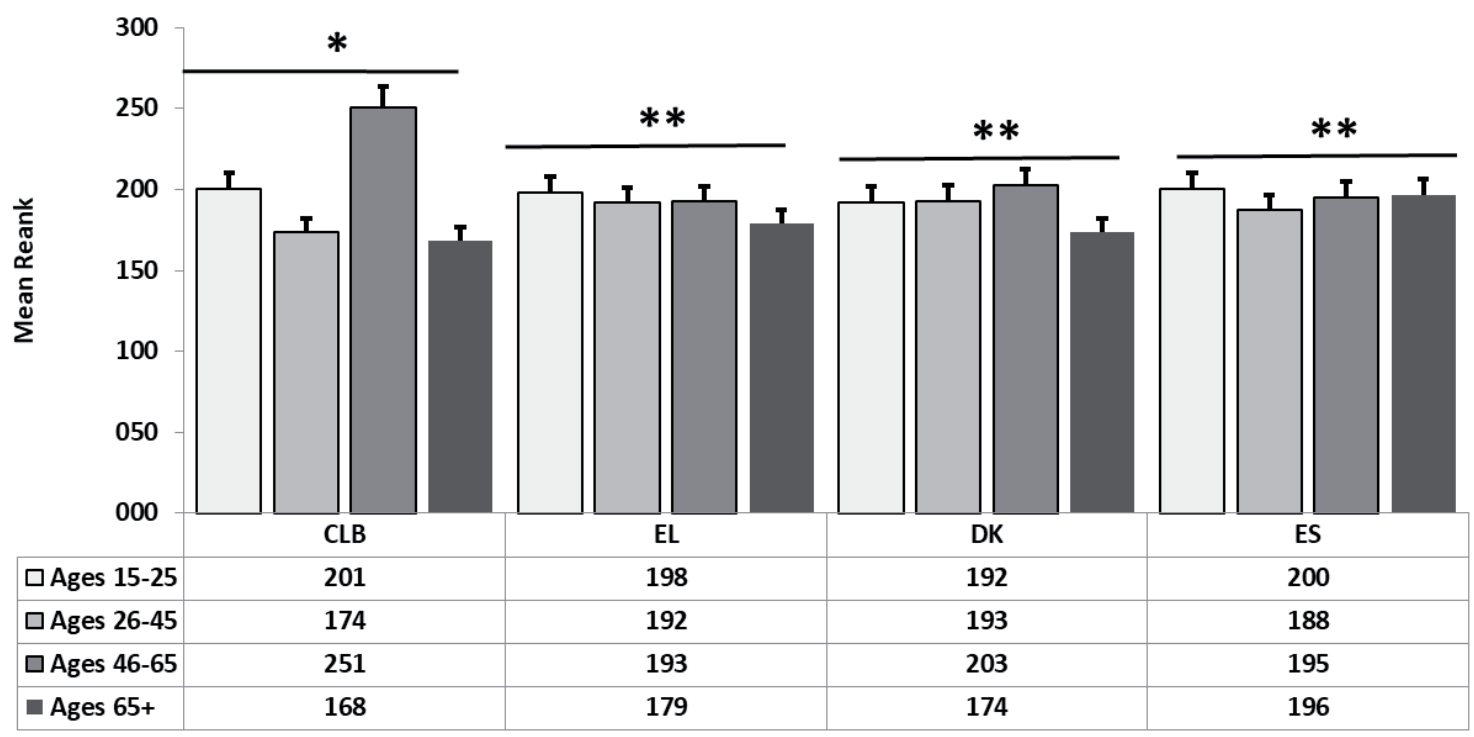

Environmetal Education (Ages)

Fig. 4. Environmental education at the perspective of ages. At the age of 46-65, respondents have sufficient knowledge of clean living behavior (CLB), and disaster knowledge (DK) compared to other ages. Meanwhile, at the age of 15-25, respondents have a good understanding of environmental literacy (EL) and environmental sensitivity (ES). Bar (Mean rank of ages), Bar error (Standard error). $(* \mathrm{p}<0.05)$ and $(* * \mathrm{p}>0.05)$. 


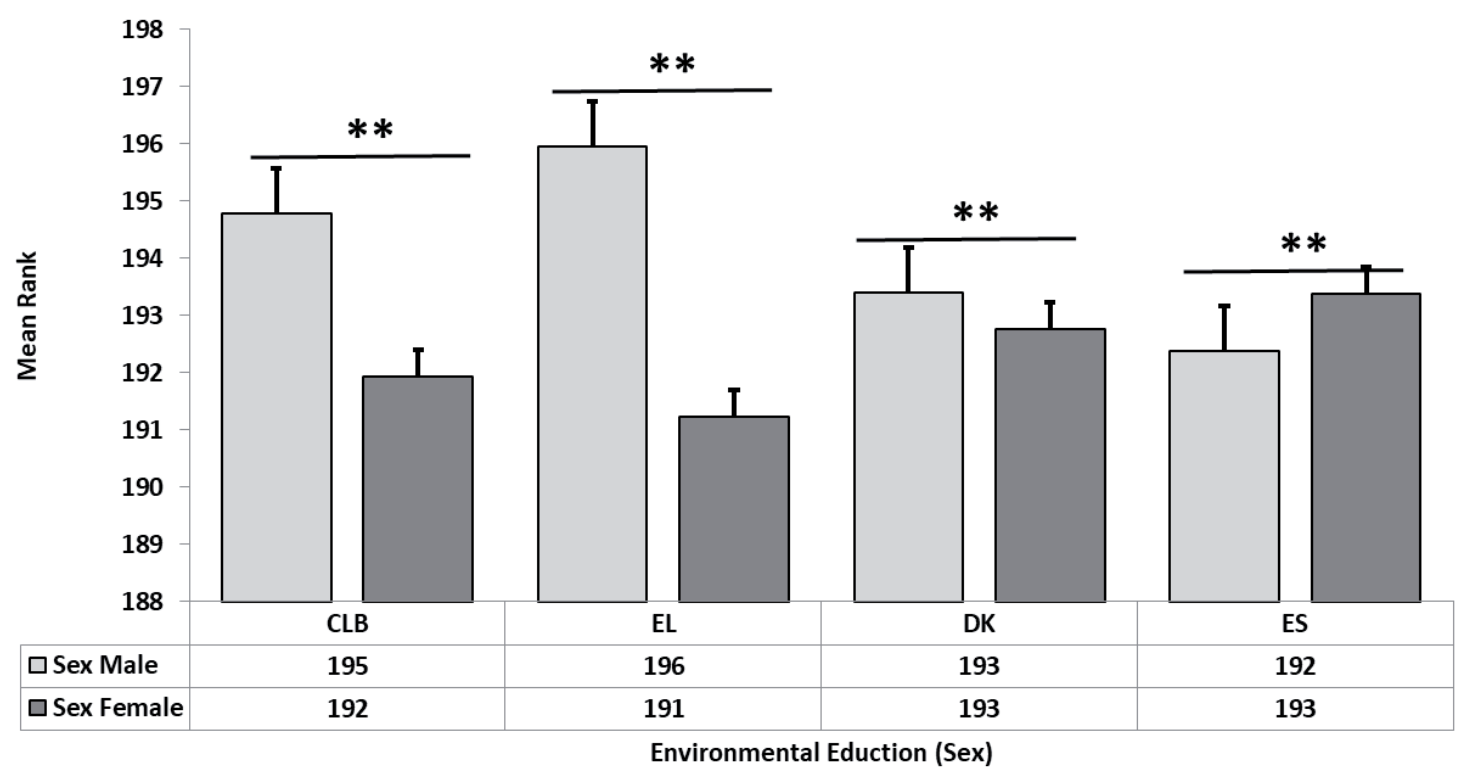

Fig. 5. Environmental education in the perspective of sex. For males, respondents have sufficient knowledge of clean living behavior (CLB), environmental literacy (EL), and disaster knowledge (DK) compared to female groups. The female group had a better understanding of environmental sensitivity (ES) than the male group. Bar (Mean rank of sex), Bar error (Standard error). $(* \mathrm{p}<0.05$ ) and $(* * \mathrm{p}>0.05)$.

disaster knowledge has a perfect marginal homogeneity. Disaster knowledge with environmental sensitivity has a good relationship, and environmental sensitivity with clean living behavior has a low relationship (Fig. 1). In Fig. 2, the same commitment from the people who live in the coastal area to understanding environmental literacy, environmental sensitivity, and disaster knowledge. The attitude of clean living behavior shows that there are differences between the three regions. This difference is because the people living in the three regions have experienced different ways of understanding clean life attitudes according to their respective cultures.

Clean living is closely related to the area's state and condition inhabited by the community, including awareness and commitment to clean living [44]. Moreover, people living in coastal, urban, and inland regions can be determinants of a clean living's attitude or behavior. The research findings explained that disaster knowledge has a close relationship with environmental education variables, environmental literacy, and environmental sensitivity. It assumed that respondents who live in coastal, urban and inland areas have good attitudes or knowledge about disasters. This attitude tends to be influenced by environmental literacy and environmental sensitivity, while disaster knowledge always affects clean living behavior [45].

Fig. 3 shows the respondents from the three regions (coastal, urban and inland) have a culture of clean living behavior (CLB) and knowledge of disaster knowledge (DK) that is different from the three regions (coastal, urban, and inland). This difference shows that the culture or attitude of the community dramatically affects clean living behavior. Besides, respondents from coastal areas specifically have a good understanding of environmental literacy (EL), and environmental sensitivity (ES) compared to urban and inland regions. However, these attitudes are still good in both areas.

In Fig. 4, it can be seen that respondents aged 46-65 have sufficient knowledge or culture of clean living behavior (CLB), and knowledge of disaster knowledge (DK) compared to other age groups. It is estimated that those over 40 years of age have a relationship with previous life experiences about disasters to provide knowledge about these two aspects. Furthermore, at the age of $15-25$, respondents have a good understanding of environmental literacy (EL) and environmental sensitivity (ES). Age 15-25 years old is considered a phase of adaptation learning to the environment, so this study's findings correlate with good behavioral responses to the environment.

In Fig. 5, it is reported that the male and female types have sufficient knowledge of clean living behavior (CLB), environmental literacy (EL), and disaster knowledge (DK) compared to the female group. The female group had a better understanding of environmental sensitivity (ES) than the male group. These two characteristics are influenced by life behavior factors, experiences, and public and environmental safety activities. Even though the two have different attitudes towards environmental education variables, they still have a sense of environmental safety.

Data from Figs 3, 4, and 5 reported that people's knowledge (area), age, and gender regarding environmental education in coastal, urban, and inland regions have different perspectives on their understanding of clean living behavior and disaster knowledge environmental literacy also environmental 
sensitivity. This difference shows the culture or attitudes between communities towards environmental education, apart from being influenced by regional demographics and community behavior practiced from generation to generation about a healthy and clean way of life [46]. This study also found that over 40 years of age have excellent environmental education knowledge because over 40 are thought to have good intelligence and experience related to environmental care related to previous life experiences about disasters [47]. The results of this study correlate with good behavioral responses to the environment. Next, the male group understands environmental education related to clean living behavior, environmental literacy, and disaster knowledge. Meanwhile, the female group has a good experience of environmental sensitivity. These findings show that the attitudes between men and women have the same commitment to protecting the environment's safety.

Based on the analysis of the research results, it shows that the three research areas of coastal, urban, and inland generally have high knowledge or attitudes towards clean living behavior $(63.10 \%)$, followed by environmental literacy (61\%), environmental sensitivity $(52.70 \%)$, and disaster knowledge $(45.50 \%)$. It is assumed that clean living behavior can contribute to environmental literacy, environmental sensitivity, and disaster knowledge. Increased understanding of clean living behavior can serve as a reference for environmental safety people. Disaster knowledge is always influenced by the element of clean living and environmentally sensitive behavior [48].

The research results in Table 3 show that disaster knowledge possessed by coastal, urban and inland communities, even though only $45.50 \%$ that affects the understanding of environmental literacy, environmental sensitivity, and clean living behavior. On December 26, 2004, Aceh, Indonesia, experienced the earthquake and tsunami disaster, which has provided lessons for the people of Aceh. Learning about disaster knowledge has helped Aceh understand environmental literacy, syncytialization of environmental changes, and increased awareness of clean living behaviors. This research correlates with learning conducted by the people of Aceh, Indonesia, where disaster knowledge has a positive relationship with environmental literacy, environmental sensitivity, and clean living behavior. This understanding is an effort always to be friendly with the environment. Good knowledge of disasters can provide preventive action for people to always live in a clean environment and sensitive to the environment [49].

Fig. 6 explains that people who live in the coastal, urban and inland areas have high knowledge or attitudes towards environmental education variables. Clean living behavior $(63.10 \%)$ is a highly committed environmental education tool, followed by environmental literacy (61\%), environmental sensitivity $(52.70 \%)$, and disaster knowledge $(45.50 \%)$. Based on the criteria level, the highest understanding of clean living behavior

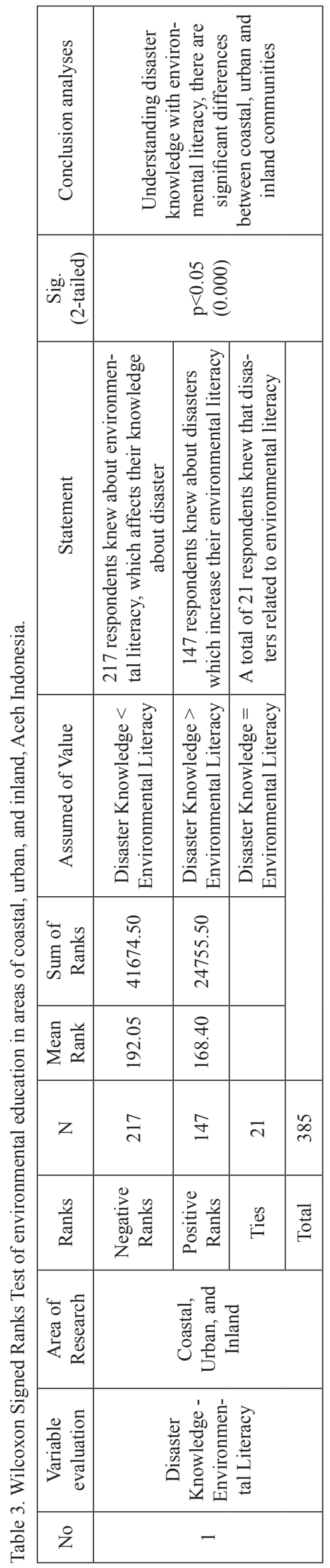




\begin{tabular}{|c|c|c|c|c|c|c|c|c|c|c|c|}
\hline \multicolumn{4}{|c|}{ 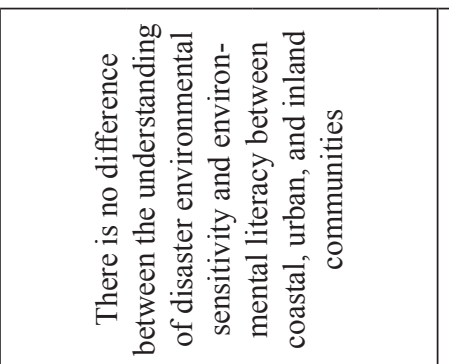 } & \multicolumn{4}{|c|}{ 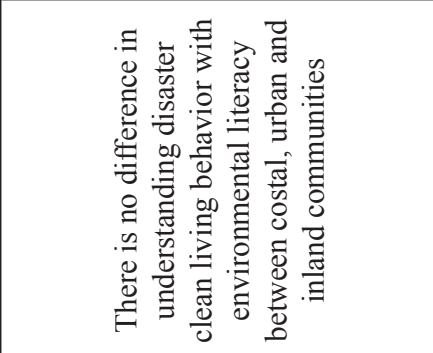 } & \multicolumn{4}{|c|}{ 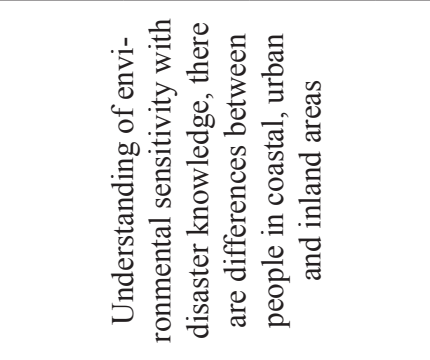 } \\
\hline \multicolumn{4}{|c|}{$\begin{array}{l}n \hat{n} \\
0.0 \hat{n} \\
\hat{0} \hat{e}\end{array}$} & \multicolumn{4}{|c|}{ 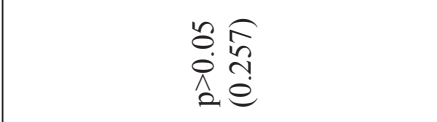 } & \multicolumn{4}{|c|}{$\begin{array}{l}n \\
o \\
\dot{\theta} \\
\dot{v} \\
o\end{array}$} \\
\hline 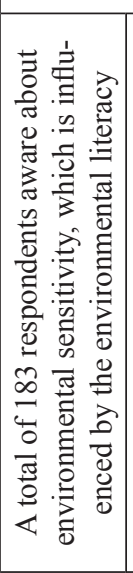 & 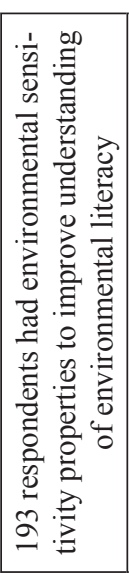 & 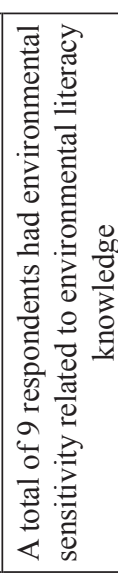 & & 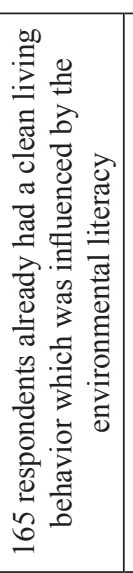 & 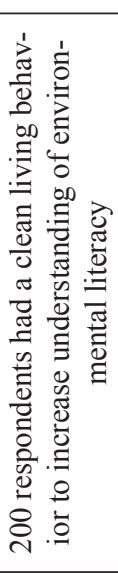 & 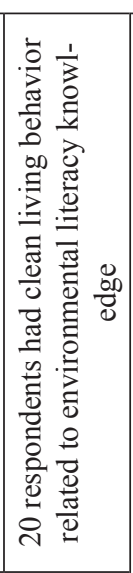 & & 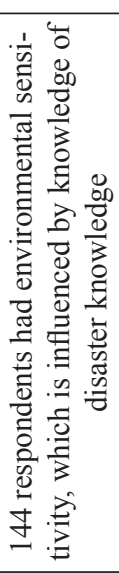 & 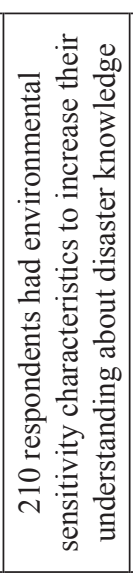 & 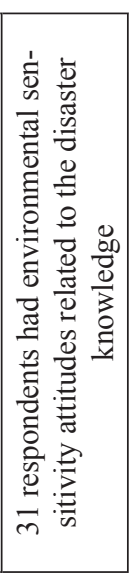 & \\
\hline 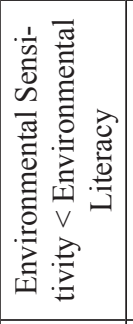 & 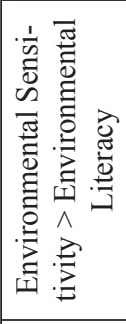 & 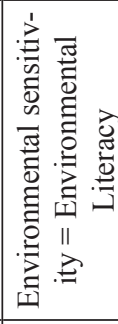 & & 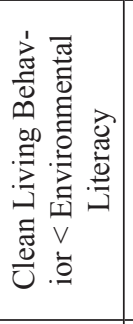 & 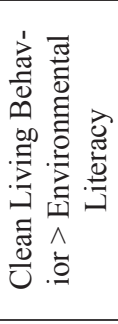 & 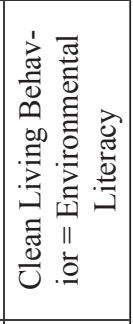 & & 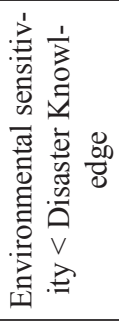 & 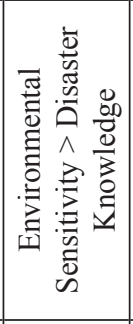 & 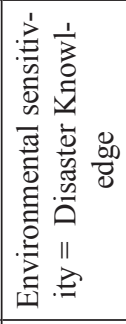 & \\
\hline $\begin{array}{l}8 \\
\stackrel{0}{0} \\
\stackrel{9}{m}\end{array}$ & $\begin{array}{l}8 \\
0 \\
0 \\
0 \\
0 \\
\text { n }\end{array}$ & & & $\underset{m}{\stackrel{n}{\Xi}}$ & $\begin{array}{l}0 \\
n \\
\infty \\
\infty \\
0 \\
n \\
m\end{array}$ & & & $\begin{array}{l}\stackrel{0}{n} \\
\infty \\
\infty \\
\infty \\
\tilde{\lambda}\end{array}$ & $\begin{array}{l}0 \\
n \\
n \\
\infty \\
\infty \\
\infty\end{array}$ & & \\
\hline $\begin{array}{l}\underset{g}{g} \\
\stackrel{\infty}{\infty} \\
-1\end{array}$ & 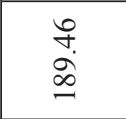 & & & $\begin{array}{l}\hat{n} \\
\infty \\
\infty \\
\infty\end{array}$ & 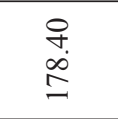 & & & 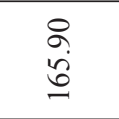 & 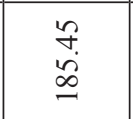 & & \\
\hline$\stackrel{\infty}{-}$ & $\underline{\Omega}$ & $a$ & $\begin{array}{c}\infty \\
\infty \\
\infty\end{array}$ & $\ddot{z}$ & $\stackrel{\sim}{~}$ & ‡े & $\begin{array}{c}\infty \\
\infty \\
\infty\end{array}$ & 寺 & $\stackrel{ }{\stackrel{\sim}{\sim}}$ & $\bar{m}$ & $\begin{array}{l}\infty \\
\infty \\
\infty\end{array}$ \\
\hline 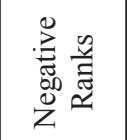 & 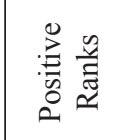 & $\stackrel{\mathscr{\varrho}}{=}$ & $\mid \begin{array}{l}\bar{\sigma} \\
\stackrel{\tilde{\sigma}}{\circ}\end{array}$ & 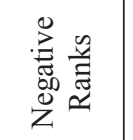 & 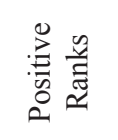 & $\stackrel{\mathscr{\varrho}}{\triangleq}$ & $\begin{array}{l}\bar{\pi} \\
0 \\
0\end{array}$ & 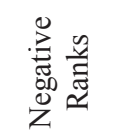 & 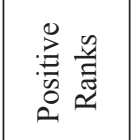 & $\stackrel{\mathscr{\Xi}}{\ominus}$ & 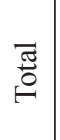 \\
\hline & 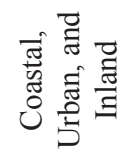 & & & & 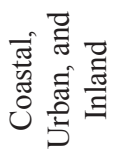 & & & & 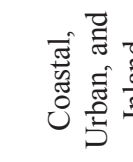 & & \\
\hline & 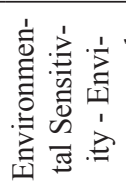 & 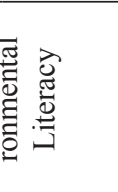 & & & 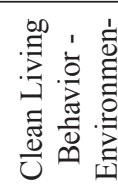 & & & & 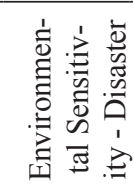 & & \\
\hline & $\sim$ & & & & $n$ & & & & $\nabla$ & & \\
\hline
\end{tabular}




\begin{tabular}{|c|c|c|c|c|c|c|c|}
\hline \multicolumn{4}{|c|}{ 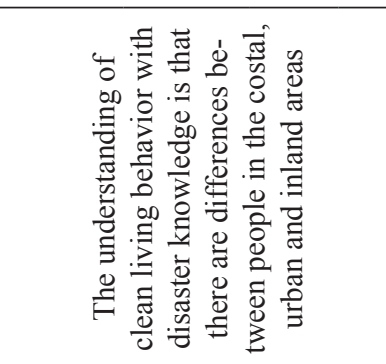 } & \multicolumn{4}{|c|}{ 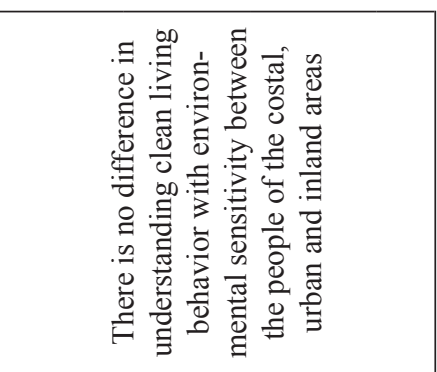 } \\
\hline \multicolumn{4}{|c|}{ 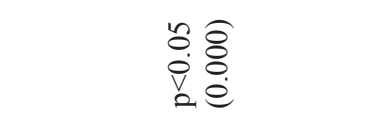 } & \multicolumn{4}{|c|}{$\begin{array}{l}\hat{2} \infty \\
\stackrel{\infty}{*} \\
\hat{2} \tilde{e}\end{array}$} \\
\hline 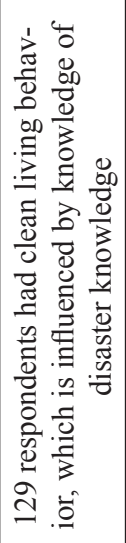 & 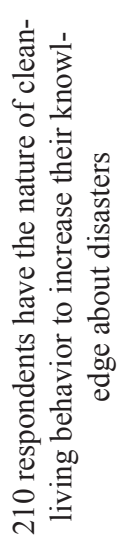 & 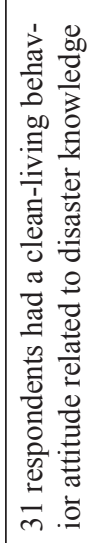 & & 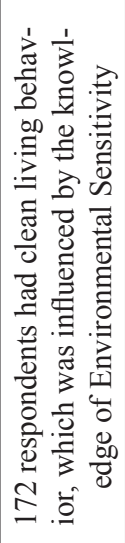 & 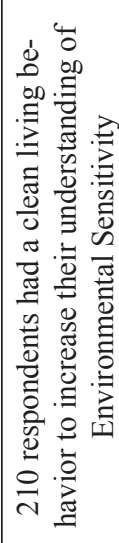 & 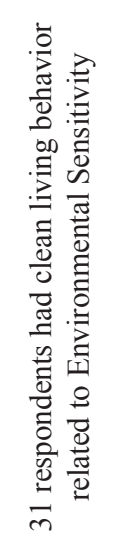 & \\
\hline 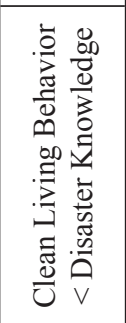 & 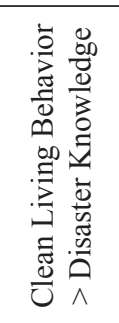 & 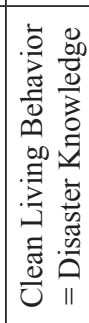 & & 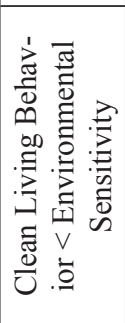 & 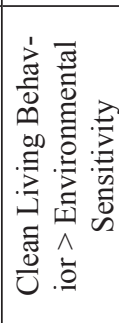 & 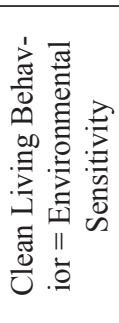 & \\
\hline $\begin{array}{l}8 \\
\stackrel{\infty}{\infty} \\
\frac{\infty}{\pi}\end{array}$ & 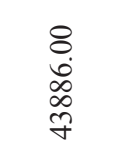 & & & 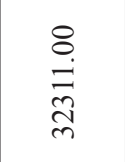 & 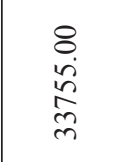 & & \\
\hline$\frac{\Delta}{\Delta}$ & $\begin{array}{l}n \\
\tilde{n} \\
\infty \\
\infty\end{array}$ & & & $\begin{array}{l}n \\
\infty \\
\infty \\
\infty\end{array}$ & 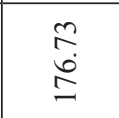 & & \\
\hline సे & $\stackrel{\varpi}{\sim}$ & તี & 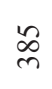 & $\stackrel{\mathbb{I}}{=}$ & $\bar{\sigma}$ & $\approx$ & $\begin{array}{l}n \\
\infty \\
m\end{array}$ \\
\hline 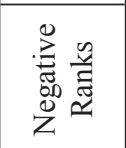 & 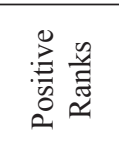 & $\stackrel{\mathscr{\vartheta}}{\oplus}$ & స్ & 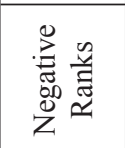 & 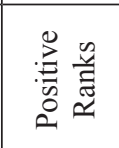 & $\stackrel{n}{\cong}$ & \begin{tabular}{|l}
$\bar{\pi}$ \\
$\stackrel{5}{0}$
\end{tabular} \\
\hline \multicolumn{3}{|c|}{ 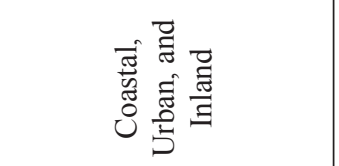 } & & \multicolumn{4}{|c|}{ 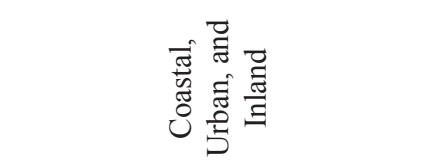 } \\
\hline \multicolumn{3}{|c|}{ 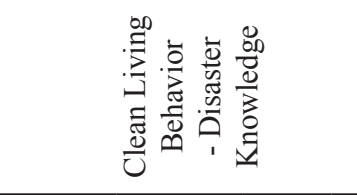 } & & \multicolumn{4}{|c|}{ 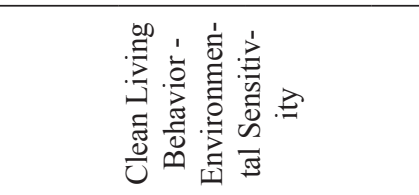 } \\
\hline \multicolumn{4}{|c|}{ in } & \multicolumn{4}{|c|}{6} \\
\hline
\end{tabular}




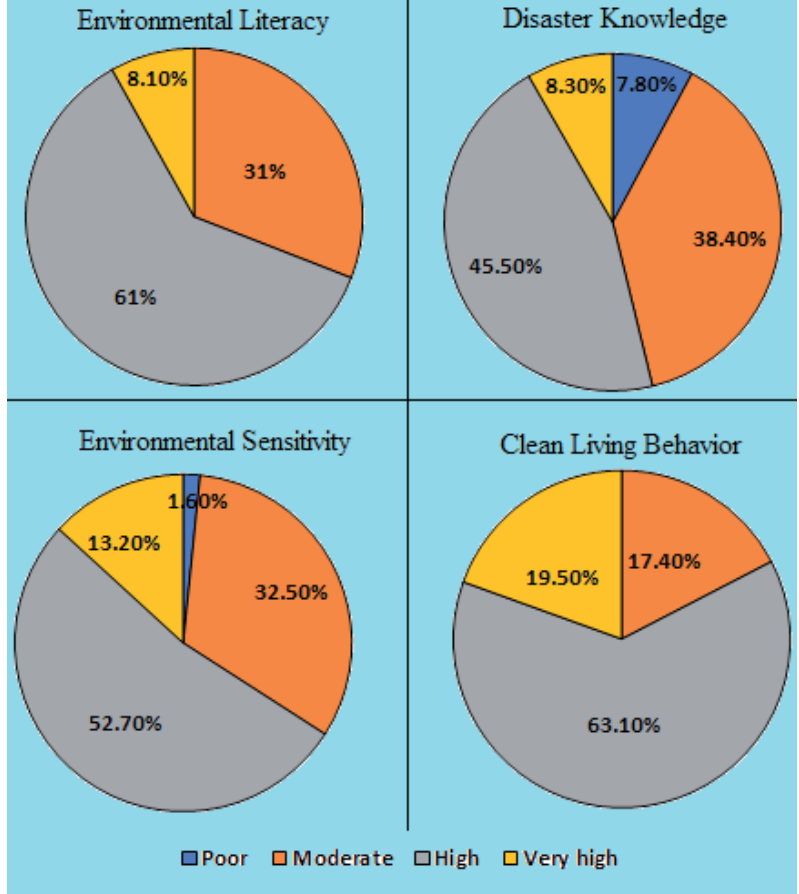

Fig. 6. Scale trend of respondents' attitudes towards environmental education perspectives. In general, majority of respondents have relatively high attitudes or knowledge about environmental literacy, disaster knowledge (45.50\%), environmental sensitivity, and environmental behavior in both coastal, urban, and inland areas.

in the three regions reached $19.50 \%$, followed by environmental sensitivity (13.20\%), disaster knowledge $(8.30 \%)$, and environmental literacy $(8.10 \%)$. The rest included in the criteria was level moderate and poor.

The data analysis, which was performed using AMOS 22.0, aims to predict the correlation between the variables used. It is based on the view that this research fulfilled all requirements, theoretical basis, sample size, and proposed assumptions. Therefore the Amos software was considered appropriate [40]. Following the analysis results, the correlation model of the variables, namely environmental literacy and sensitivity, disaster knowledge, and environmental behavior, is obtained in Fig. 7.
Fig. 7 shows the relationship between environmental education variables analyzed in this study. These results interpreted that the culture of clean living behavior can be a reference for increasing knowledge of disaster, environmental sensitivity, and environmental literacy. Environmental literacy has a positive relationship with environmental cleanliness behavior. These results show that environmental cleanliness behavior is affected by environmental literacy in society. This finding is also consistent with previous studies, which stated that environmental literacy significantly affects environmental behavior and promotes its emergence in every individual [41]. These behaviors are affected by various factors [50-52], educational level [53], prosocial [52-54], and cultural conditions of the community including the existing policies in an area.

However, other studies stated that as an essential aspect of environmental literacy, awareness causes individuals to consider their environment, receive related information, correctly understand and evaluate problems, and consciously regulate their behaviors [55]. Community environmental literacy is a determining factor affecting regional development in clean living behavior [56]. Furthermore, these variables play an essential role in creating better public health.

Disaster knowledge has a positive relationship with clean living behavior. It means that individuals with adequate environmental cleanliness behavior are also affected by appropriate knowledge of disaster. This finding is also supported by the research, which stated that environmental knowledge affects behavior through different pathways and tends to possess implications or interventions that seek to enhance environmentally friendly behavior [57]. Another research stated a significant relationship between sanitation knowledge and a person's educational level. Subsequently, formal education offers the essential knowledge and a better understanding of the environment [58].

Increasing environmental knowledge is effectively carried out through outreach or socialization with certain institutions in overcoming related problems. There is a relationship between environmental knowledge and citation practices. Individuals that possess environmental knowledge tend to have a better

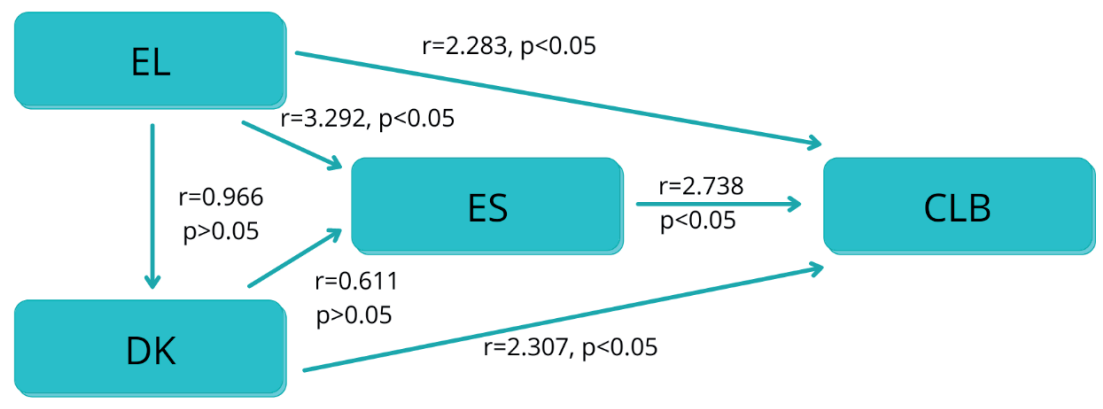

Fig. 7. The correlation path analysis of research questions model of environmental literacy (EL), disaster knowledge (DS), environmental sensitivity (ES), and clean-living behavior (CLB). Value (r) indicates a correlation, and value (p) indicates significance. 
awareness of environmental management. Meanwhile, knowledge (objective and subjective) affects proenvironmental behavior [57-59].

Environmental sensitivity has a positive relationship with environmental cleanliness behavior, which is strongly supported by sensitivity. It is consistent with previous studies that stated that environmental behavior is affected by certain attitudes and actions [60]. People's recycling waste behavior correlates with social norms. However, some other research stated that students from developing and developed countries have differences related to external factors such as culture, and environmental structure, which tends to affect their behavior towards the environment [61]. Sensitivity to environmental problems is related to consumer choice behavior in purchasing environmentally friendly products [62]. The environmental awareness, product features, promotional activities, and prices positively affect consumer behavior in making friendly purchases [63].

Environmental literacy also has a positive relationship with environmental sensitivity. Generally, people have good environmental sensitivity because they possess adequate environmental literacy. Previous studies supported this research, which stated a significant relationship between environmental literacy and attention. The framework that connects environmental literacy is formed based on attitudes and behavioral intentions [64]. Moreover, environmental experience has a significant effect on its literacy, and mass media is serving as the primary source of information [65].

Explicit attitudes affect behavior through environmentally friendly behavior pathways. Individual acquisition of responsible environmental behavior triggers changes in the context of environmental literacy related to global politics. Students that spend much time watching television and interacting with electronic media do not show any concern for the environment. Furthermore, environmental literacy positively affects green consumption behavior both partially and simultaneously [66-67].

However, environmental literacy has no relationship with disaster knowledge. These results show that disaster and environmental knowledge have different dimensions. These findings are consistent with previous studies, which stated that no significant difference was detected in undergraduates' environmental knowledge from two universities. Community environmental awareness is inseparable from natural conditions, particularly in rural areas. Therefore environmental education needs to be embraced at an early age to create awareness and patterns of behavior in accordance with expectations. Disaster knowledge as part of environmental knowledge greatly assists the community in environmental literacy. Therefore, one of the methods used to avoid this disaster is to abandon their current thoughts and behavior. In addition, education is the most effective tool for creating a sustainable environmental system.
Conceptual knowledge acquired in an educational institution has no natural effect without applying reality. On the contrary, people who acquire disaster knowledge directly through family and community socialization tend to handle these issues effectively. The people of Simeulue-Aceh, Indonesia, demonstrated that we could offer relevant disaster knowledge, thereby minimizing casualties during the 2004 tsunami. This knowledge is manifested in the community through attitudes and sensitivity to the natural environment. Furthermore, this condition was different in other Acehnese communities because the inhabitants of Banda Aceh City, the west coast, and the central region had numerous victims due to the natural disasters. The leading cause is that a person's environmental and disaster knowledge was not adequately integrated with attitudes and environmental sensitivity in daily activities.

Disaster knowledge has no relationship with environmental sensitivity. These results indicate that environmentally sensitive people do not necessarily possess the proper understanding of the disaster. This research is supported by previous findings, which stated that environmental concern is not related to disaster preparedness. The teacher has a satisfactory level of environmental knowledge. However, the level of action displayed is poor. The environmental knowledge is insignificantly related to environmental attitudes [68]. Furthermore, another research stated that environmental school students had poor preservation and utilization attitudes than those in non-environmental institutes [69].

However, some other research reported that tourists' appropriate environmental knowledge of the Penghu Islands is associated with stronger environmental sensitivity, which is positively related to their attachment to certain places [70]. This condition is thought to be different because the research subjects are tourists that already knew the destination. Moreover, it is inversely proportional to this research subject: the local people with environmental sensitivity do not harmonize with their knowledge.

\section{Conclusions}

The research findings illustrated that environmental literacy, disaster knowledge, and environmental sensitivity are positively correlated with clean living behavior. Literacy about the environment, disaster knowledge, and environmental sensitivity are essential aspects of encouraging clean living behavior. The government, therefore, should pay intention to the elements by incorporating the concepts into the school curriculum as early as possible at the primary level. Moreover, the most significant correlation showed by disaster knowledge with environmental literacy, environmental sensitivity with disaster knowledge, and clean living behavior with disaster knowledge $(\mathrm{p}<0.05)$. It indicates that environmental literacy is crucial 
to increase the environmental sensitivity among the Acehnese people of Indonesia.

The research findings recommended that environmental education programs be integrally loaded to the school curriculum, and people should repeatedly be informed through multi-channel social media elements by involving various government agencies and non-governmental organizations regarding environmental aspects. The community needs to be provided with an in-depth knowledge of disaster and environmental sensitivity related to its cleanliness. Collaboration between institutions, significantly higher educations, other non-formal institutes, and government agencies related to the environment is intended to increase disaster knowledge and environmental literacy, sensitivity, and cleanliness behavior in the Acehnese community, Indonesia.

\section{Acknowledgments}

This research was funded by Universitas Syiah Kuala through "Penelitian Lektor Kepala" scheme, grant number: 121/UN11.2.1/PT.01.03/PNBP/2021.

\section{Conflict of Interest}

The authors declare no conflict of interest.

\section{References}

1. CHU H., LEE E.A., RYUNG KO H., HEE SHIN D., NAM LEE M., MEE MIN B., HEE KANG K. Korean Year 3 Children's Environmental Literacy: A prerequisite for a Korean environmental education curriculum. International Journal of Science Education, 29 (6), 731, 2007.

2. ZAREIE B., NAVIMIPOUR N.J. The impact of electronic environmental knowledge on the environmental behaviors of people. Computers in Human Behavior, 59, 1, 2016.

3. RAMADHAN S., SUKMA E., INDRIYANI V. Environmental education and disaster mitigation through language learning. IOP Conference Series: Earth and Environmental Science, 314, 012054, 2019.

4. ABUN D. Environmental Attitude and Environmental Behavior of Catholic Colleges' Employees in Ilocos Sur, Philippines. Texila International Journal Of Academic Research, 4 (1), 23, 2017.

5. ARBUTHNOTT K.D. Education for sustainable development beyond attitude change. International Journal of Sustainability in Higher Education, 10 (2), 152, 2009.

6. ARORA L., AGARWAL S. Knowledge, attitude, and practices regarding waste management in selected hostel students of the university of Rajasthan, Jaipur. Nt J Chem Environ Pharm Res, 2 (1), 40, 2011.

7. BISWAS A., ROY M. Green products: An exploratory study on the consumer behavior in emerging economies of the East. Journal of Cleaner Production, 87, 463, 2015.

8. BOEVE-DE PAUW J., VAN PETEGEM P. The Effect of Flemish Eco-Schools on Student Environmental
Knowledge, Attitudes, and Affect. International Journal of Science Education, 33 (11), 1513, 2011.

9. BOTETZAGIAS I., DIMA A.F., MALESIOS C. Extending the Theory of Planned Behavior in the context of recycling: The role of moral norms and of demographic predictors. Resources, Conservation and Recycling, 95, 58, 2015.

10. BOZTEPE A. Green Marketing and Its Impact on Consumer Buying Behavior. European Journal of Economic and Political Studies, 5 (1), 5, 2012.

11. CARLINA E., DJUKRI. Science Project-based Learning Integrated with Local Potential to Promote Student's Environmental Literacy Skills. Advanced Journal of Social Science, 4 (1), 1, 2018.

12. CARLING P.C. Optimizing Health Care Environmental Hygiene. Infectious Disease Clinics of North America, 30 (3), 639, 2016.

13. CHEKIMA B., CHEKIMA S., SYED KHALID WAFA S.A.W., IGAU O.A., SONDOH JR S.L. Sustainable consumption: the effects of knowledge, cultural values, environmental advertising, and demographics. International Journal of Sustainable Development \& World Ecology, 23, 210, 2016.

14. CHENG T.M., WU H.C. How do environmental knowledge, environmental sensitivity, and place attachment affect environmentally responsible behavior? An integrated approach for sustainable island tourism. Journal of Sustainable Tourism, 23 (4), 557, 2015.

15. CHU Z., XI B., SONG Y., CRAMPTON E. Taking out the trash: Household preferences over municipal solid waste collection in Harbin, China. Habitat International, 40, 194, 2013.

16. CHWIALKOWSKA A., BHATTI W.A., GLOWIK M. The influence of cultural values on pro-environmental behavior. Journal of Cleaner Production, 268, 122, 2020.

17. COLLÉONY A., WHITE R., SHWARTZ A. The influence of spending time outside on experience of nature and environmental attitudes. Landscape and Urban Planning, 187, 96, 2019.

18. CUNNINGHAM D.D. Literacy Environment Quality in Preschool and Children's Attitudes Toward Reading and Writing. Literacy Teaching and Learning, 12 (2), 19, 2008.

19. YUSUF R., MAIMUN S., FAJRI I., SAPUTRA J. A Comparison of Student Environmental Literacy: Public and Islamic Schools in Banda Aceh, Indo-nesia. International Journal of Innova-tion, Creativity and Change, 12 (9), 222, 2020.

20. EILAM E., TROP T. Environmental Attitudes and Environmental Behavior - Which Is the Horse and Which Is the Cart? Sustainability, 4 (9), 2210, 2012.

21. ERDOĞAN M., KOSTOVA Z., MARCINKOWSKI T. Components of Environmental Literacy in Elementary Science Education Curriculum in Bulgaria and Turkey. EURASIA Journal of Mathematics, Science and Technology Education, 5 (1), 2009.

22. SCHOLZ R.W., BINDER C.R. Environmental literacy in science and society: From knowledge to decisions. Cambridge University Press, 2011.

23. KIDMAN G., CASINADER N. Developing Teachers' Environmental Literacy through Inquiry-based Practices. EURASIA Journal of Mathematics, Science and Technology Education, 15 (6), 2019.

24. ERHABORA N., U. DON J. Impact of Environmental Education On the Knowledge and Attitude of Students Towards the Environment. International Journal of Environmental \& Science Education, 11 (12), 2018. 
25. FANG W.T., LIEN C.Y., HUANG Y.W., HAN G., SHYU G.S., CHOU J.Y., NG E. Environmental Literacy on Ecotourism: A Study on Student Knowledge, Attitude, and Behavioral Intentions in China and Taiwan. Sustainability, 10 (6), 1886, 2018.

26. SIMMONS D. Papers on the development of environmental education. North American Association for Environmental Education, Troy, Ohio, USA, 1995.

27. GRAJAL A., LUEBKE J.F., KELLY L.A.D., MATIASEK J., CLAYTON S., KARAZSIA B.T., SAUNDERS C.D., GOLDMAN S.R., MANN M.E., STANOSS R. The complex relationship between personal sense of connection to animals and self-reported pro-environmental behaviors by zoo visitors: Sense of Connection to Animals. Conservation Biology, 31 (2), 322, 2017.

28. GRAY K. From Content Knowledge to Community Change: A Review of Representations of Environmental Health Literacy. International Journal of Environmental Research and Public Health, 15 (3), 466, 2018.

29. HARTINI N., DIAN A., DEWI T.K., KURNIAWAN A. Improving urban environment through public commitment toward the implementation of clean and healthy living behaviors. Psychology Research and Behavior Management, 10, 79, 2017.

30. HEAD L., KLOCKER N., AGUIRRE-BIELSCHOWSKY I. Environmental values, knowledge and behaviour: Contributions of an emergent literature on the role of ethnicity and migration. Progress in Human Geography, 43 (3), 397, 2019.

31. HILL R.J. Civic engagement and environmental literacy. New Directions for Adult and Continuing Education, 20 (135), 4, 2012.

32. HOFFMANN R., MUTTARAK R. Learn from the past, prepare for the future: Impacts of education and experience on disaster preparedness in the Philippines and Thailand. World Development, 96, 32, 2017.

33. HSU S.J. The Effects of an Environmental Education Program on Responsible Environmental Behavior and Associated Environmental Literacy Variables in Taiwanese College Students. The Journal of Environmental Education, 35 (2), 37, 2004.

34. HUANGFU G., LV F., SHENG C., SHI X. Effect of workplace environment cleanliness on judgment of counterproductive work behavior. Social Behavior and Personality: An International Journal, 45 (4), 599, 2017.

35. JATAU A.A. Knowledge, Attitudes and Practices Associated with Waste Management in Jos South Metropolis, Plateau State. Mediterranean Journal of Social Sciences, 4 (5), 119, 2013.

36. KAMIL P.A., UTAYA S., SUMARMI UTOMO D.H. Improving disaster knowledge within high school students through geographic literacy. International Journal of Disaster Risk Reduction, 43, 101, 2020.

37. KAVAZ D., ÖZTOPRAK H. Environmental Awareness of University Students on White Cheese Waste Water. EURASIA Journal of Mathematics, Science and Technology Education, 13 (12), 8003, 2017.

38. KINSLOW A.T., SADLER T.D., NGUYEN H.T. Socioscientific reasoning and environmental literacy in a fieldbased ecology class. Environmental Education Research, 25 (3), 388, 2019.

39. KLINE R.B. Principles and practice of structural equation modeling ( $3^{\text {rd }}$ ed). Guilford Press, 2011.

40. KOLLMUSS A., AGYEMAN J., Mind the Gap: Why do people act environmentally and what are the barriers to pro-environmental behavior? Environmental Education Research, 8 (3), 239, 2002.

41. KUBIATKO M. The Environmental Literacy of Lower Secondary School Pupils, High School and College Students. Journal of Environmental Science and Engineering Technology, 2 (1), 2, 2014.

42. KURUPPUARACHCHI J., SAYAKKARAGE V., MADURAPPERUMA B. Environmental Literacy Level Comparison of Undergraduates in the Conventional and ODLs Universities in Sri Lanka. Sustainability, 13 (3), 1056, 2021.

43. TUNCER G., ERTEPINAR H., TEKKAYA C., SUNGUR S., Environmental attitudes of young people in Turkey: effects of school type and gender. Environmental Education Research, 11 (2), 215, 2007.

44. LARSON L.R., STEDMAN R.C., COOPER C.B., DECKER D.J., Understanding the multi-dimensional structure of pro-environmental behavior. Journal of Environmental Psychology, 43, 112, 2015.

45. LEVINE D.S., STRUBE M.J. Environmental Attitudes, Knowledge, Intentions and Behaviors Among College Students. The Journal of Social Psychology, 152 (3), 308, 2012.

46. LEVY B.L.M., MARANS R.W. Towards a campus culture of environmental sustainability: Recommendations for a large university. International Journal of Sustainability in Higher Education, 13 (4), 365, 2012.

47. LIANG S.W., FANG W.T., YEH S.C., LIU S.Y., TSAI H.M., CHOU J.Y., NG E. A Nationwide Survey Evaluating the Environmental Literacy of Undergraduate Students in Taiwan. Sustainability, 10 (6), 1730, 2018.

48. LIU S.Y., YEH S.C., LIANG S.W., FANG W.T., TSAI H.M. A National Investigation of Teachers' Environmental Literacy as a Reference for Promoting Environmental Education in Taiwan. The Journal of Environmental Education, 46 (2), 114, 2015.

49. MAMADY K., Factors influencing attitude, safety behavior, and knowledge regarding household waste management in Guinea: a cross-sectional study. Journal of environmental and public health, 2016.

50. MARDOTILLAH M., GUNAWAN B., SOEMARWOTO R.S., RAKSANAGARA A.S., Peran faktor pemungkin dan penguat pada akses jamban sehat perkotaan. Jurnal Antropologi: Isu-Isu Sosial Budaya, 20 (December), 165, 2018.

51. MAURER M., BOGNER F.X. Modelling environmental literacy with environmental knowledge, values and (reported) behaviour. Studies in Educational Evaluation, 65, 100-863, 2020.

52. MERCER J. Disaster risk reduction or climate change adaptation: Are we reinventing the wheel? Journal of International Development, 22 (2), 247, 2010.

53. MILFONT T.L., DUCKITT J. The structure of environmental attitudes: A first- and second-order confirmatory factor analysis. Journal of Environmental Psychology, 24 (3), 289, 2004.

54. MOFFA M., CRONK R., FEJFAR D., DANCAUSSE S., PADILLA L.A., BARTRAM J. A systematic scoping review of environmental health conditions and hygiene behaviors in homeless shelters. International Journal of Hygiene and Environmental Health, 222 (3), 335, 2019.

55. MUFLIHAINI M.A., ERTANDO A., SURYADARMA How is the attitude of students' environmental literacy through the myth (Ficus sp.) in adiwiyata school? Journal of Physics: Conference Series, 1440, 012, 2020. 
56. NAAEE. Guidelines for the initial preparation of environmental educators. North American Association for Environmental Education, 2000.

57. NGURE F.M., REID B.M., HUMPHREY J.H., MBUYA M.N., PELTO G., STOLTZFUS R.J. Water, sanitation, and hygiene (WASH), environmental enteropathy, nutrition, and early child development: Making the links. Ann. NY Acad. Sci., 118, 2014.

58. NOGAMI T. What Behaviors We Think We Do When a Disaster Strikes: Misconceptions and Realities of Human Disaster Behavior. In Integrating Disaster Science and Management (pp. 343-362). Elsevier, 2018.

59. NONAKA I., NISHIGUCHI T. Knowledge emergence social, technical, and evolutionary dimensions of knowledge creation. Oxford University Press, 2001.

60. NURWAQIDAH S., RAMLI M. Environmental Literacy Mapping Based on Adiwiyata and Non Adiwiyata at Junior High School in Ponorogo. KnE Social Sciences, 3 (15), 179, 2019.

61. NURWIDODO N. The Role of Eco-School Program (Adiwiyata) towards Environmental Literacy of High School Students. European Journal of Educational Research, 9 (3), 1089, 2020.

62. OKTARI R.S., MUNADI K., IDROES R., SOFYAN H. Knowledge management practices in disaster management: Systematic review. International Journal of Disaster Risk Reduction, 51, 101, 2020.

63. ORELLANA-RÍOS A., POZO-LLORENTE M.T., POZA-VILCHES M. DE F. Pro-environmental Attitudes and Teaching Practice in Secondary Schools Located in Natural Protected Areas from the Perception of Students: The Case of Níjar Fields (Almería -Spain). Procedia Social and Behavioral Sciences, 237, 1112, 2017.
64. OTTO S., PENSINI P., Nature-based environmental education of children: Environmental knowledge and connectedness to nature, together, are related to ecological behaviour. Global Environmental Change, 47, 88, 2017.

65. PATHIRAGE C., SENEVIRATNE K., AMARATUNGA D., HAIGH R. Managing disaster knowledge: Identification of knowledge factors and challenges. International Journal of Disaster Resilience in the Built Environment, 3 (3), 237, 2012.

66. PUJIATI A., SETIAJI K., OKTAVILIA S. Impact of Social Influence and Environmental Literacy on Green Consumption Behaviour: A case study of Indonesian students. International Journal of Advanced Science and Technology, 29 (6), 2020.

67. RACHMATULLAH A., LEE J.K., HA M. Preservice science teachers' ecological value orientation: A comparative study between Indonesia and Korea. The Journal of Environmental Education, 51 (1), 14, 2020.

68. VEISI H., LACY M., MAFAKHERI S., RAZAGHI F. Assessing environmental literacy of university students: A case study of Shahid Beheshti University in Iran. Applied Environmental Education \& Communication, 18 (1), 25, 2019.

69. RAMDAS M., MOHAMED B., Impacts of Tourism on Environmental Attributes, Environmental Literacy and Willingness to Pay: A Conceptual and Theoretical Review. Procedia - Social and Behavioral Sciences, 144, 378, 2014.

70. YUA S-L., CHUA Y-C., TSAIB H-M. Environmental changes and building resilient community in Penghu Islands. Journal of Marine and Island Cultures, 5 (2), 126, 2016. 